\title{
SIGNWRITING: A PROPOSTA DE LEITURA PARA ALUNOS SURDOS PELA TRANSCRIÇÃO DA LÍNGUA BRASILEIRA DE SINAIS
}

\author{
Edmarcius Carvalho Novaes \\ Universidade Vale do Rio Doce (UNIVALE), Governador Valadares, \\ Minas Gerais, Brasil \\ Edmara Carvalho Novaes \\ Faculdade Presidente Antônio Carlos de Governador Valadares \\ (UNIPAC), Governador Valadares, Minas Gerais, Brasil \\ JÉssica Rocha de MOURA \\ Universidade Federal de Juiz de Fora (UFJF), Juiz de Fora, Minas \\ Gerais, Brasil
}

\begin{abstract}
Resumo: Uma nova estratégia de ensino baseada na transição direta dos sinais da Libras - Língua Brasileira de Sinais, denominada Signwriting, apresenta-se como importante instrumento pedagógico para alunos surdos. Nesse sentido, este artigo objetiva identificar como essa estratégia se constitui instrumento pedagógico para o estímulo à leitura de crianças surdas. A metodologia empregada foi revisão bibliográfica (STUMF, 2005; CAPOVILLA, 2005; NOVAES, 2014) e documental. Conclui-se que o Signwriting é de significativa importância no desenvolvimento de alunos surdos, fazendo com que consigam, de forma mais aprimorada, adquirirem a sua própria Língua de Sinais - e ao mesmo tempo a Língua Portuguesa enquanto segunda língua - a partir da leitura realizada com esta forma de transição dos sinais.
\end{abstract}

Palavras-chave: Signwriting. Leitura. Língua Brasileira de Sinais. Alunos surdos.

\section{INTRODUÇÃO}

A proposta de inclusão escolar de minorias sociais, com base na “Declaração de Salamanca" e executada pelo Ministério da Educação (MEC) em nosso país, referenciada nas Diretrizes Nacionais para a Educação Especial na Educação Básica (BRASIL, 1994), orienta a inclusão de crianças surdas em salas de aula do sistema regular de ensino, público ou privado, e apresenta o Tradutor-Intérprete de Libras como apoio técnico aos alunos surdos para a aquisição dos conteúdos apresentados nas aulas. Isto ocorre porque a Libras é a língua oficial da comunidade surda no Brasil. 
Segundo Quadros e Karnopp (2004) a Libras é uma língua de modalidade visualespacial e possui cinco parâmetros linguísticos que a constituem e a legitimam enquanto uma língua estruturalmente organizada: configuração das mãos, ponto de articulação, movimento, direção/orientação, expressões faciais e corporais.

A partir de 1974, nos Estados Unidos, um novo mecanismo pedagógico ganhou notoriedade acadêmica: trata-se do Signwriting. Terminologia de origem inglesa, que em português significa "escrita de sinais". Refere-se ao método de escrita e leitura expressa das configurações de mãos, os movimentos, direção, as expressões faciais e os pontos de articulação das línguas de sinais. Configura-se ferramenta metodológica pois se apresenta útil às práticas pedagógicas, e por ser um recurso capaz de produzir um registro escrito das línguas de sinais sem que tenha que passar pela tradução comumente realizada pelas línguas orais. Enquanto mecanismo pedagógico, o Signwriting pode contribuir para que o aluno surdo obtenha um melhor desempenho escolar, pois as crianças surdas brasileiras apresentam dificuldades na escrita e leitura da Língua Portuguesa, sua segunda língua.

A proposta de transcrição direta dos sinais, que é utilizada em mais de 40 países em escolas, universidades, associações de surdos e outros espaços relacionados às comunidades surdas, segundo Capovilla (2005), pode acabar com a descontinuidade entre as línguas de sinais e línguas orais para os surdos inclusos nas escolas regulares.

No entanto, os estudos sobre esta ferramenta ainda são incipientes no Brasil. Por isso, o presente trabalho justifica-se pela necessidade de maior divulgação deste sistema de escrita e leitura de sinais, para futuras pesquisas e projetos acadêmicos que estimulem o processo de ensino-aprendizagem dos surdos a partir do registro e leitura dos sinais, assim como apoie as atividades pedagógicas de profissionais da educação especial.

\section{LIBRAS: COMUNIDADES, IDENTIDADES E CULTURA SURDA}

A Libras é a Língua de Sinais oriunda e comumente utilizada pela comunidade surda brasileira, e que possui o status de língua por dispor de estrutura gramatical e regras próprias, a partir de um sistema de organização com os mesmos níveis linguísticos das línguas orais-auditivas, nas áreas da fonologia, morfologia, sintaxe, semântica e pragmática, além da possibilidade de se constituir apresentando vivências de variações linguísticas (NOVAES, 2014; ALMEIDA; NOVAES, 2017).

Isto ocorre porque a Libras é constituída por unidades mínimas de significação, que são caracterizadas por parâmetros baseados em uma articulação sistemática, voltada para a utilização fundamental do espaço visual. Segundo Stumpf (2002), é a análise desses parâmetros que permite a compreensão dos níveis linguísticos da Libras, se constituindo em:

a) Configurações de mãos - diz respeito à formatação dos sinais;

b) Ponto de articulação - relaciona-se à localização onde são feitos os sinais;

c) Movimento - a utilização do espaço de forma ampla em que cada sinal tenha (ou não) sua própria articulação e mobilidade; 
d) Orientação - indica o posicionamento certo do movimento, por exemplo, se ele é de cima para baixo, à esquerda ou direita, etc.

e) Expressão facial ou corporal - indica exatamente o sentido lexical em que se quer fazer entendido.

Os sinais na Libras são formados a partir da combinação destas unidades gramaticais, ou seja, da combinação desses parâmetros, considerados itens necessários para a formação de qualquer palavra.

Nas línguas orais, o locutor se comunica oralmente utilizando o som da fala e o interlocutor recebe a informação através da audição. Na língua de sinais, o locutor manda a informação utilizando-se dos parâmetros para a realização do(s) sinal(is) e o interlocutor recebe a informação visualmente.

No entanto, independentemente da Língua de Sinais que é utilizada em cada país, o seu aprendizado e a interação com outros indivíduos que partilham desta outra forma de comunicação fazem da identidade surda uma crescente descoberta enquanto campo epistemológico, com foco nas capacidades intelectuais e sociais a partir da diferença sociolinguística dos sujeitos surdos.

No Brasil, a Língua Brasileira de Sinais teve seu reconhecimento como sistema linguístico e amparo legal para seus usuários pela Lei Federal $n^{\circ} 10.436$, de 24 de abril de 2002 (regulamentada pelo Decreto Federal $n^{\circ}$. 5.626, de 22 de dezembro de 2005). A partir disso, firmou-se como principal articuladora da construção comunicativa da comunidade surda, de sua identidade e cultura, constituindo-se como o marco mais importante diante da batalha dessa comunidade na sua emancipação, interação e socialização, e na luta de reconhecimentos de direitos específicos a partir da diferenciação sociolinguística (ALMEIDA; NOVAES, 2017).

Segundo Perlin (2004, p. 77-78), "as identidades surdas são construídas dentro das representações possíveis da cultura surda", e em razão disso, "elas moldam-se de acordo com maior ou menor receptividade cultural assumida pelo sujeito". Essas identidades surdas refletem as formas pelas quais as pessoas surdas se percebem no mundo e nas relações que estabelecem consigo mesmas e com os outros, reconhecendo-se a partir da diferença sociolinguística.

Já a Comunidade Surda é compreendida como aquela que não é só constituída por pessoas surdas, mas também pelos indivíduos que compõem seus círculos de convívio social, como os familiares, amigos, professores, tradutores-intérpretes e interessados em se aprofundar na Libras e na Cultura Surda. São exemplos de comunidades surdas os agrupamentos sociais em associações representativas, os grêmios esportivos, os grupos religiosos, dentre outros (NOVAES, 2014; ALMEIDA; NOVAES, 2017).

Tanto as identidades surdas como as comunidades surdas se organizam por meio de uma dada cultura denominada "Cultura Surda", que pode ser compreendida como

o jeito de o sujeito surdo entender o mundo e de modificá-lo a fim de torná-lo acessível e habitável ajustando-os com as suas percepções visuais, que contribuem para a definição das identidades surdas e das "almas" das comunidades surdas" (STROBEL, 2008, p. 30).

Assim, a Libras não é apenas uma linguagem. Trata-se de uma língua, com sua organização gramatical, desenvolvida em uma modalidade visual gestual, não 
estabelecida através da modalidade oral-auditiva, mas através da modalidade espaço-visual. Por ser o principal meio de desenvolvimento do processo cognitivo do pensamento de um ser humano surdo, e como língua oficial da comunidade surda, pode ser apreendida por qualquer pessoa, seja ela pertencente ou não a uma comunidade de surdos. A aquisição se dá a partir da interação com outros usuários, para um melhor desenvolvimento, pois como destaca Caldeira (1998):

(...) a melhor performance comportamental pode-se dever, além da exposição mais precoce à língua de sinais, a um melhor manejo educativo (...) ou seja, aquisição da língua de sinais demanda do aluno muito motivação interesse e deve ser praticada constantemente com outros usuários, interpretes, evitando esquecimento e ampliando o conhecimento da mesma (CALDEIRA, 1998, p. 21-22).

Atualmente existem instituições governamentais de educação especial na perspectiva da educação inclusiva, que se ocupam em ensinar a Libras para crianças surdas matriculadas no ensino regular desde a educação infantil, bem como dispõe de tradutores-interpretes especializados para um acompanhamento individual nas dependências das instituições de ensino, acompanhando e traduzindo as aulas que estão sendo ministradas, o que facilita o processo de inclusão de crianças surdas na escola e na sociedade em geral.

\section{SIGNWRITING: O REGISTRO E A LEITURA}

O Signwriting, a "escrita de sinais", é um sistema de representação gráfica das Línguas de Sinais, que segundo Stumf (2005) se dá de forma idêntica aos sistemas de escritas alfabéticos que representam os fonemas componentes das palavras nas diversas línguas orais-auditivas.

Enquanto sistema de escrita visual direta, o sistema pode registrar qualquer língua de sinais sem passar pela tradução da língua falada, baseando-se na escrita de diferentes símbolos visuais para representar as diversas dimensões relevantes das Línguas de Sinais: configurações de mãos; expressões faciais; pontos de articulação, etc.

Trata-se de um sistema de escrita que pode ser empregado fonologicamente para o registro cientifico da Libras, ou foneticamente, para a sua escrita prática, uma vez se tratar de

(...) é um sistema de escrita com características gráficos esquemáticos, que permite uma representação de textos de línguas de sinais através de uma forma intuitiva e de fácil compreensão. O sistema é constituído de um conjunto de símbolos e um conjunto de regras de escrita, definidos para representar os diversos aspectos fonetico-fonologicos das línguas de sinais (COSTA et.al., 2014, p. 254).

Criado primeiramente pela norte americana Valerie Suton, em 1974, para descrever os movimentos das danças, mais tarde o sistema chamou a atenção de pesquisadores dinamarqueses que pesquisavam uma forma eficaz de descrever as Línguas de Sinais e assim facilitasse a leitura dos sinais. Ao longo dos anos foram desenvolvidos diversos estudos até se chegar à forma em que se apresenta atualmente. 
Segundo Capovilla (2005) ele é uma forma de se realizar a leitura da informação apresentada pela língua de sinais, e possui as mesmas propriedades da língua falada: fonemas (língua falada) e quiremas ${ }^{1}$ (no Signwriting), utilizando-se de símbolos visuais para retratar situações propostas. É grande sua importância fonológica como registro cientifico da língua de sinais, e foneticamente no registro escrito do dia a dia. Até então, a única forma de se registrar as Línguas de Sinais eram através de registros em vídeo outro importante instrumento para a comunidade surda e para a práticas pedagógicas de leitura com alunos surdos.

Destaca-se ainda que a aquisição do Signwriting proporciona um aprimoramento na língua materna da Comunidade Surda, levando a uma melhor organização da mesma e consequentemente, um enriquecimento e padronização da língua e de sua leitura, com efeitos na cultura, enquanto instrumental de interação espacial e temporal e de registro histórico da língua.

Também destaca-se que, apesar de ter sido desenvolvido como um registro para língua de sinais, hoje ele é usado como sistema de escrita prático empregado na comunicação entre surdos e ouvintes. Suas aplicações no Brasil estão na escrita e leitura de contos infantis, registro em Dicionário Trilíngue da Língua Brasileira de Sinais (Língua de Sinais, Língua Portuguesa e Língua Inglesa), em Enciclopédias da Língua de Sinais Brasileira e no sistema de comunicação via rede de computadores.

Stumf (2002) ressalta a importância do Signwriting quando afirma que "os surdos precisam de uma escrita que represente os sinais visuais e espaciais com os quais se comunicam", uma vez que não se pode "(...) aprender bem uma escrita que reproduz os sons que não conseguem ouvir" (p. 63).

Neste sentido, a aquisição da escrita de sinais possibilita a tradução para a língua de sinais de um volume infinito de informações. Ao mesmo tempo, a escrita é importante para a comunicação em qualquer nível, podendo ser registrados de pensamentos a um livro. Portanto, a escrita de sinais possibilita a leitura e a escrita dos sinais por seus usuários, independentemente do tipo ou nível do projeto a ser desenvolvido na Libras.

Em relação à transcrição, sabe-se que o Signwriting funciona como um sistema de escrita alfabética. Segundo Stumf (2005), a escrita alfabética é um sistema gerativo que possibilita ler qualquer palavra nova. Ela permite a autoaprendizagem pelo leitor. $O$ processo aos poucos contribui para criar uma representação ortográfica de cada palavra, que será então lida pela rota lexical, o que acontece com as palavras já bem conhecidas e que aparecem com frequência.

Na Língua Portuguesa existem as letras do alfabeto para compor o significado dos sons da fala, que unidas formam as palavras, ao se ler. No Signwriting este alfabeto é realizado a partir da configuração de mão. Tal mecanismo é dividido em dez categorias: mãos, contato das mãos, faces, movimentos do corpo e da cabeça, ombro, membros, inclinação do corpo e da cabeça, localização, movimentos de dinâmicas e pontuação. A estrutura do Signwriting é composta por configuração de mão, movimento, expressão facial e corporal. Veja: 
FIGURA 1: Configurações de mão

\begin{tabular}{|c|c|c|c|c|}
\hline \multicolumn{5}{|c|}{ 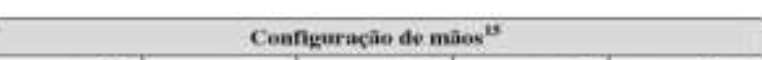 } \\
\hline 190 & 마 & ㅁ. & 무 & a \\
\hline (स) & (1) & ㅁ. & $\sigma$ & a \\
\hline 103 & ᄃ & व & d 63 & $d$ \\
\hline$d \Leftrightarrow$ & 7 삼정 & $=0$ & 당 & \\
\hline م & 0 (46) & 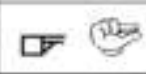 & 다 (स्2 & \\
\hline () & $\square$ & 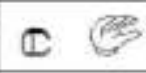 & II & \\
\hline n & F & & & \\
\hline 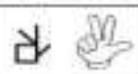 & 입 & & & \\
\hline 4) (10) & $y$ & *ै & if & \\
\hline$\forall$ & 占透 & पे & 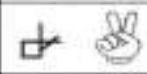 & \\
\hline & & 1996 & 当 《 & \\
\hline & च & & & \\
\hline
\end{tabular}

Fonte: (SILVA, 2009, p. 32-33)

FIGURA 2: Configurações básicas da mão aberta, circular ou fechada.

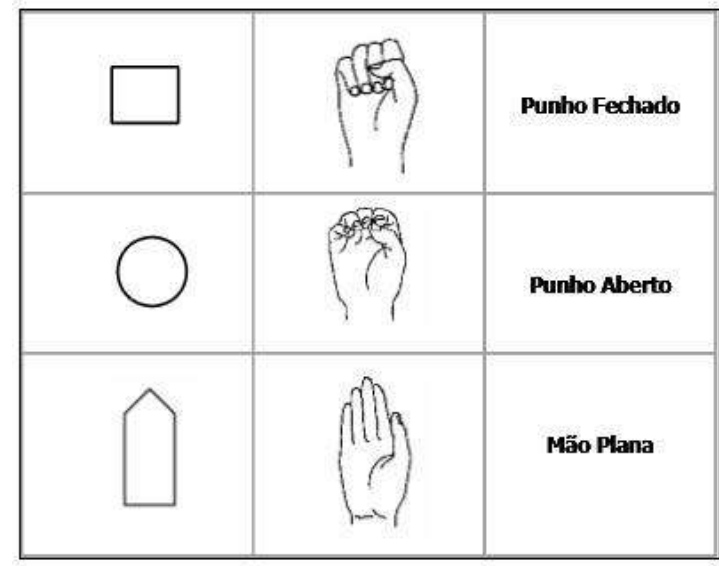

Fonte: (STUMPF, 2005, p.61) 
NOVAES, E. C.; NOVAES, E. C.; MOURA, J. R.

FIGURA 3: Linhas dos dedos

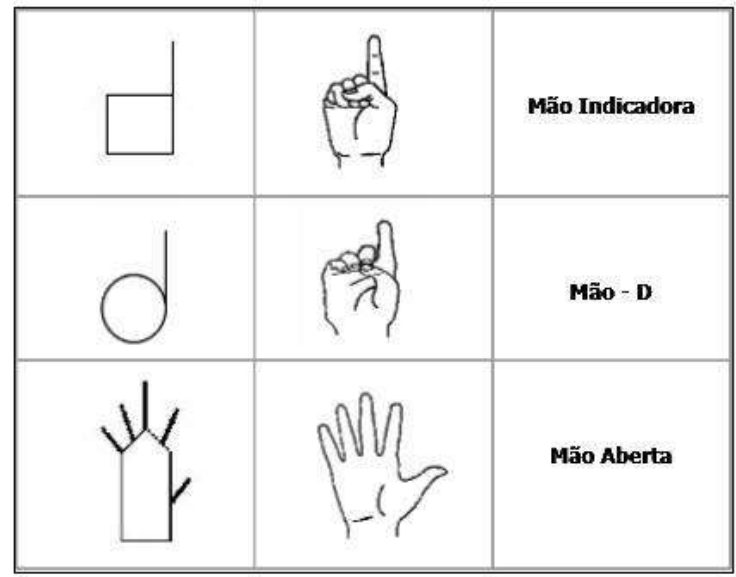

Fonte: (STUMPF, 2005, p.65)

FIGURA 4: Orientação da palma:

\begin{tabular}{|c|c|c|c|c|c|}
\hline \multicolumn{7}{|c|}{ Orientação das palmas } \\
\hline & 0 & 0 & $\hat{\mathbf{u}}$ & $\hat{U}$ & 0 \\
$\begin{array}{c}\text { Palma para } \\
\text { frente }\end{array}$ & $\begin{array}{c}\text { Palma para } \\
\text { olado } \\
\text { esquerdo }\end{array}$ & $\begin{array}{c}\text { Paima para } \\
\text { dentro }\end{array}$ & $\begin{array}{c}\text { Palma para } \\
\text { baixo }\end{array}$ & $\begin{array}{c}\text { Palma para } \\
\text { cima }\end{array}$ & $\begin{array}{c}\text { Palma para } \\
\text { olado } \\
\text { direilo }\end{array}$ \\
\hline
\end{tabular}

Fonte: (SILVA, 2009, p. 33)

FIGURA 5: Exemplo
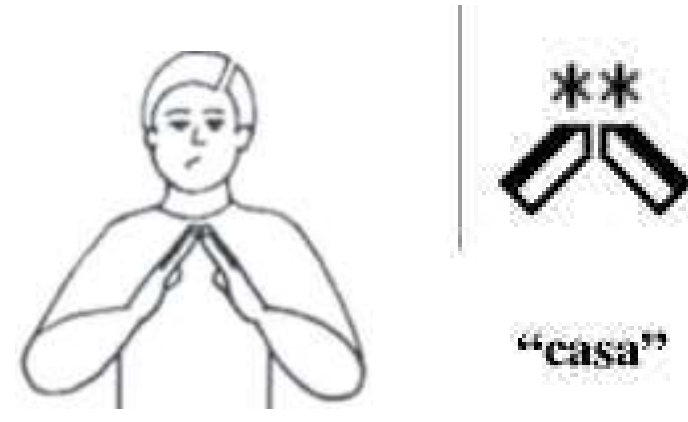

Fonte: (STUMPF, 2005, p.77) 
FIGURA 6: Movimentos
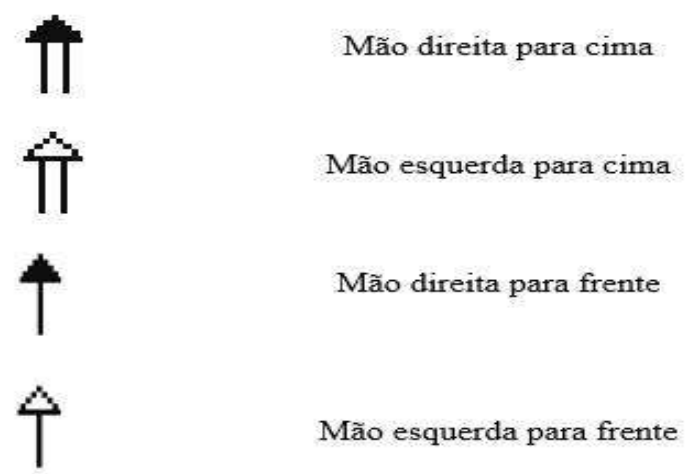

Fonte: (STUMPF, 2005, p.77)

Figura 7: Plano vertical

\begin{tabular}{|c|c|c|c|c|c|}
\hline \multicolumn{6}{|c|}{ Movimento (plano vertical) } \\
\hline & & 표 & An & 표 & $\forall \pi$ \\
\hline niti & ㅍㅛㅠ & 吸 & & & \\
\hline 니 & & 33 & 刍 & & 霖 \\
\hline h & $\approx$ & (9) & (2) & & \\
\hline ठో) & th & 雨 & 雨 & 霖 & 雨 \\
\hline 包 & 西 & 4 & 霖 & & \\
\hline
\end{tabular}

Fonte: (SILVA, 2009, p. 34-35) 
NOVAES, E. C.; NOVAES, E. C.; MOURA, J. R.

FIGURA 8: Plano Horizontal

\begin{tabular}{|c|c|c|c|c|c|}
\hline \multicolumn{6}{|c|}{ 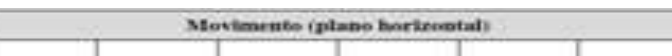 } \\
\hline$\uparrow$ & 个 & $\uparrow$ & $\leftrightarrow$ & +4 & דיד \\
\hline N+t & $\tau$ & $x$ & $\tau$ & $\tau$ & $\tau$ \\
\hline N & N & 千 & 本 & 乎 & -2 \\
\hline$f$ & -2 & $\varepsilon$ & จ & E & s \\
\hline b & $-F^{*}$ & 2 & $\mathscr{F}$ & 22 & -22 \\
\hline$\tau$ & 6. & $t$ & 4 & E & b \\
\hline $\mathfrak{S}$ & ?. & $\tau$ & to & tet & tato \\
\hline$t \rightarrow t$ & to & $\cdots$ & 2 & $\rightarrow$ & $\infty$ \\
\hline$m$ & $\sim$ & $\sim$ & $\approx$ & $m$ & $\sim$ \\
\hline 3 & 3 & 3 & 3 & $\xi$ & 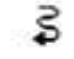 \\
\hline$\epsilon$ & ats & 2 & $Q 2$ & 4 & $\approx$ \\
\hline$\$$ & $\approx$ & 数 & 青 & $\$$ & $=$ \\
\hline
\end{tabular}

Fonte: (SILVA, 2009, p. 35-36)

FIGURA 9: Movimentos no plano diagonal:

\begin{tabular}{|c|c|c|c|c|}
\hline \multicolumn{5}{|c|}{ Movimento (plano diagonal) } \\
\hline \# & त्रु & 【 & $\Uparrow$ & ब \\
\hline ब्ञ & t & 5 & 3 & 蛋 \\
\hline$\hat{0}$ & 3े & ro & ${ }^{\circ}$ & \\
\hline
\end{tabular}

Fonte: (SILVA, 2009, p. 36-37) 
FIGURA 10: Pontos de articulação: a cabeça, bochecha, nariz, boca, pescoço e queixo, tronco

\begin{tabular}{|c|c|c|c|c|c|}
\hline \multicolumn{6}{|c|}{ Fonto de articulacao } \\
\hline$\infty$ & $\infty$ & $\infty$ & 0 & $\leftrightarrow$ & $\rightarrow$ \\
\hline 0 & (1) & (*) & (t) & (813) & SP: \\
\hline$\subseteq 2$ & $\Theta$ & 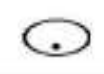 & & $D$ & $\bigcirc$ \\
\hline$\infty$ & & $\infty$ & $(\bigcirc)$ & $(\rightarrow)$ & 6 \\
\hline- & & $=$ & $=$ & $\longrightarrow$ & س \\
\hline$\rightarrow$ & & 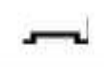 & $m$ & $\longrightarrow$ & 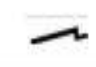 \\
\hline 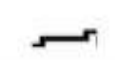 & & 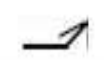 & $\nabla$ & $\nabla$ & 凶 \\
\hline
\end{tabular}

Fonte: (SILVA, 2009, p. 39)

Expressões não manuais: de acordo com Quadros e Karnopp (2004, p.60), as expressões não manuais correspondem aos movimentos da face, dos olhos, da cabeça ou do tronco. Possuem duas funções importantes: marcação de construções sintáticas (sentenças interrogativas, orações relativas, topicalizações, concordância e foco) e diferenciação de itens lexicais (marcação de referência específica, referência pronominal, partícula negativa, advérbio, grau ou aspecto).

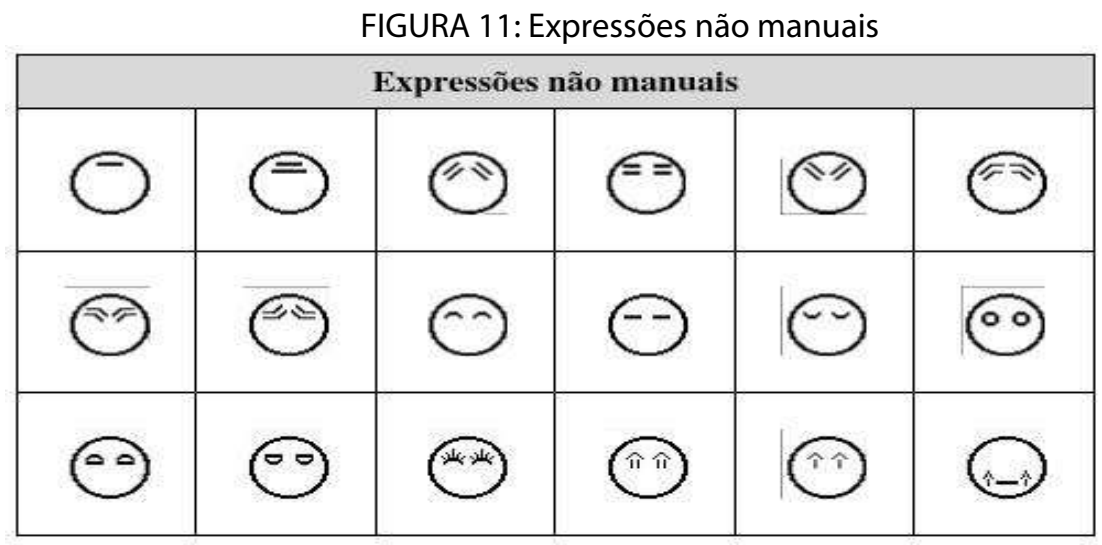

Fonte: (SILVA, 2009, p. 40-41) 


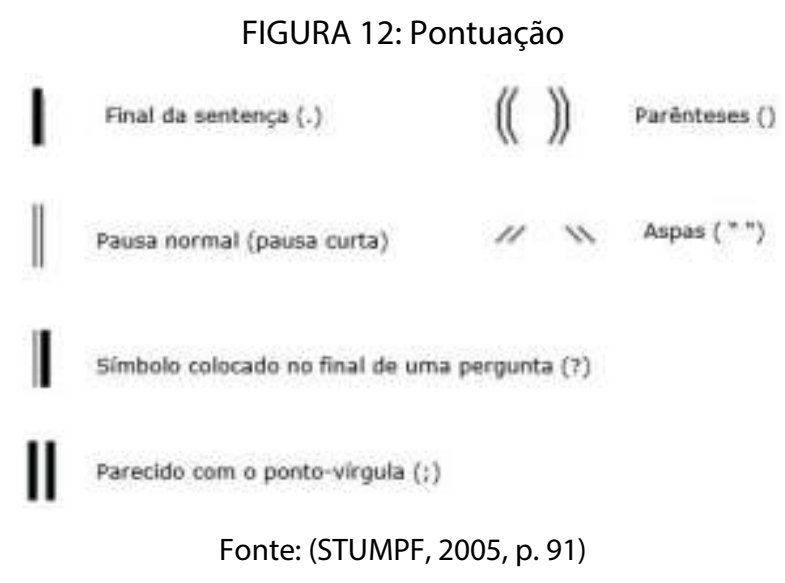

A utilização desses componentes é capaz de escrever qualquer palavra em Libras ou de realizar a leitura de qualquer texto sinalizado.

\section{A RELACAO DO SIGNWRITING COM O PROCESSO EDUCATIVO: ESCRITA, LEITURA E APRENDIZAGEM}

A Pedagogia ocupa-se do desenvolvimento de instrumentos pedagógicos que facilitam o processo de aprendizagem dos envolvidos na educação e na inclusão de crianças, de jovens, e de adultos com necessidades educacionais especiais dentro da escola regular de ensino. Neste sentido, ao longo da história, várias filosofias pedagógicas foram apresentadas para educação de crianças surdas: o Oralismo, a Comunicação Total e o Bilinguismo.

O oralismo ocupou-se de conceber uma metodologia capaz de desenvolver a fala nos indivíduos surdos. A comunicação total pressupunha que os surdos pudessem se comunicar através de qualquer forma de comunicação, e por isso, combinava a Língua de Sinais com gestos, mímicas, leitura labial, entre outros.

Atualmente no Brasil é utilizada a abordagem bilíngue no processo de alfabetização de crianças surdas; entende-se que a criança surda deve utilizar sua língua materna, a Libras (L1), frente à tarefa de se comunicar e pensar, e uma segunda língua estrangeira (no nosso caso, a Língua Portuguesa, como L2) para exercer exclusivamente a escrita e leitura.

Porém, segundo Silva, Bolsanello e Sander (2011):

Os surdos brasileiros, em sua maioria, exibem dificuldades no uso da escrita alfabética, provavelmente em razão da enorme distância entre a língua de sinais, por meio da qual o surdo organiza o seu pensamento, e o sistema alfabético, criado para representação de línguas orais (p. 140).

Sabe-se dos avanços culturais alcançados com a invenção da escrita e a necessidade que os surdos têm de darem esse salto. Segundo Capovilla (2005), ao se utilizar da escrita e leitura proposta pelo Signwriting, é possível "a reflexão sobre o 
próprio ato linguístico, o avanço e o aprimoramento constantes da linguagem como veículo do pensamento para o pleno desenvolvimento social e cognitivo" (p. 263).

A escrita é um mecanismo de extrema importância para o desenvolvimento cognitivo dos alunos, bem como de sua emancipação frente às diversas demandas do aprendizado. Para isso é necessário um sistema de escrita que traga benefícios psicológicos e sociais, permitindo ao surdo utilizar sua bagagem visual para pensar, escrever, e se fazer entender, o que se dá de forma diferente de uma criança que é ouvinte e falante, pois neste caso,

(...) há uma continuidade entre os três contextos comunicativos básicos: a comunicação transitória consigo mesma (i.e., o pensar), a comunicação transitória com outrem na relação face a face (i.e., o falar), e a comunicação perene na relação remota e mediada (i.e., o escrever) (CAPOVILLA, 2005, p. 1492).

Nesse sentido, percebe-se que no processo de aprendizagem de crianças ouvintes acontece uma continuidade dinâmica em que ela fala, pensa e escreve em uma mesma língua. Já na criança surda, espera-se muito mais: que ela pense e se comunique em sua língua de sinais primária, de modalidade espaço-visual, no entanto, frente à tarefa de escrever e de ler, que o faça por meio das palavras de uma língua oral-auditiva, e estrangeira para si.

A falha na continuidade e a diferença entre as modalidades das duas línguas fazem com que a criança surda tenha dificuldade de assimilação nos atos comunicativos durante a escrita e a leitura, o que segundo Capovilla (2002), remete a um atraso no desenvolvimento da aprendizagem:

Tal falha, antevista mas pouco analisada, é constituída de outra descontinuidade envolvendo a língua de sinais, uma descontinuidade tão importante quanto aquela que derrubou o paradigma da comunicação total e entronizou o do bilinguismo. Tão ou ainda mais importante, já que não se trata apenas da descontinuidade com algo que o paradigma do bilinguismo possa descartar, como a fala, mas da descontinuidade com algo que é tão caro ao paradigma do bilinguismo quanto para qualquer outro dos dois paradigmas (i.e., oralismo e comunicação total): a escrita alfabética (CAPOVILLA, 2002, p.142).

A substituição da escrita a partir de uma língua oral-auditiva por uma escrita que dialogue diretamente com a Língua de Sinais, equaciona o fenômeno da descontinuidade e coloca as crianças surdas em igualdade na utilização de recursos linguísticos, favorecendo o processo de aprendizagem da leitura e escrita. Neste sentido, o Signwriting é um instrumento pedagógico capaz de equacionar a descontinuidade entre os atos comunicativos, pois a escrita de sinais é feita pelos surdos de maneira intuitiva em Língua de Sinais, com a escrita própria, e consequentemente, com a possibilidade de leitura dos sinais que compõe seu sistema linguístico.

\section{CONSIDERAÇÕES FINAIS}


A escrita e a leitura são ferramentas cruciais no desenvolvimento intelectual do ser humano. Por isso é fundamental que sejam apresentadas atividades significativas também para a criança surda em seu processo de aprendizagem, em razão das dificuldades vivenciadas no seu desenvolvimento sociolinguístico. Neste processo, cabe aos educadores a busca por novas técnicas e instrumentais que promovam a emancipação dos alunos surdos frente às suas demandas no processo educativo.

É neste sentido que a escrita direta dos sinais possibilita a tentativa de uma nova abordagem metodológica à tarefa da alfabetização e letramento de crianças surdas. Este sistema é capaz de registrar as características das diferentes línguas de sinais, dando-lhes novas possibilidades em diversas áreas do conhecimento e favorecendo um processo de inclusão que se pauta pelo respeito às diferenças individuais.

Por isso, têm-se a necessidade de se pensar em uma didática que seja flexível e que ofereça o mesmo conteúdo curricular, respeitando as especificidades do aluno surdo, sem que haja perda na qualidade do ensino e da aprendizagem. Uma língua escrita diretamente dos sinais da Libras pode contribuir não só para o aprimoramento da própria Língua de Sinais, como também ao desenvolvimento cognitivo, cultural e linguístico da pessoa surda, que se encontrará estimulada em apreender as especificidades deste instrumento de escrita e leitura.

Alunos surdos, escrevendo e lendo em sua língua materna (Libras), quebra a descontinuidade existente nos atos comunicativos na abordagem bilíngue de alfabetização, uma vez que estes se dão em Libras. Em igualdade de recursos linguísticos, os alunos surdos podem ter acesso aos livros didáticos necessários no seu processo de alfabetização e letramento adaptados em SIGNWRITING - e estes materiais usados como fixadores de conteúdo. Posteriormente, apropriada a leitura dessa escrita, a criança surda pode ter bagagem intelectual que lhe servirá de base para o aprendizado de um segundo idioma, o que no caso do Brasil é a Língua Portuguesa.

Portanto, é de suma importância que pesquisadores e estudiosos brasileiros das diversas áreas do conhecimento compreendam e acompanhem o funcionamento desta ferramenta de grande utilidade pedagógica, propondo novos olhares e novas contribuições para a inclusão de alunos surdos.

Artigo recebido em: $24 / 08 / 2017$ Aprovado para publicação em: 17/02/2018

SIGNWRITING: THE READING PROPOSAL FOR DEAF STUDENTS BY THE TRANSCRIPTION OF THE BRAZILIAN SIGN LANGUAGE

ABSTRACT: A new teaching strategy based on the direct transition of signs from Libras - Brazilian Sign Language, called Signwriting, represents an important pedagogical tool for deaf students. In this sense, this article aims to identify how that strategy constitutes a pedagogical tool to stimulate the reading of deaf children. The methodology used was bibliographic review (STUMF, 2005, CAPOVILLA, 2005, AUTOR A, 2017) and documentary. It is concluded that Signwriting has significative importance in the development of deaf students, enabling them to better acquire their own Sign Language - and at the same time, the Portuguese Language as the second language - from the reading performed with this form of signal transition. 
KEYWORDS: Signwriting. Reading. Brazilian Language of Signals. Deaf students.

\section{SIGNWRITING: LA PROPUESTA DE LECTURA PARA ALUMNOS SORDOS POR LA TRANSCRIPCIÓN DE LA LENGUA BRASILEÑA DE SEÑALES}

RESUMEN: Una nueva estrategia de enseñanza basada en la transición directa de los signos de la Libras - Lengua Brasileña de Señales, denominada Signwriting, se presenta como importante instrumento pedagógico para alumnos sordos. En ese sentido, este artículo objetiva identificar cómo esa estrategia se constituye instrumento pedagógico para el estímulo a la lectura de niños sordos. La metodología empleada fue revisión bibliográfica (STUMF, 2005, CAPOVILLA, 2005, AUTOR A, 2017) y documental. Se concluye que el Signwriting es de significativa importancia en el desarrollo de alumnos sordos, haciendo que consigan, de forma más mejorada, adquirir su propia Lengua de Señales - y al mismo tiempo la Lengua Portuguesa como segunda lengua - a partir de la lectura realizada con esta forma de transición de los señales.

PALABRAS CLAVE: Signwriting. Lectura. Lengua Brasileña de Señales. Alumnos Sordos.

\section{NOTA}

1) Quiremas são unidades mínimas, etimologicamente de origem grega, significa mãos. Ressaltase que atualmente, têm-se utilizado o termo fonema ao se referir as unidades menores que compõem os sinais, e não somente aos sons de uma dada língua (PÊGO, 2013).

\section{REFERENCIAS}

ALMEIDA, A. R.; NOVAES, E. C. Contribuições do direito para a inclusão da pessoa surda: reflexões sobre uma igualdade material pelas diferenças sociolinguísticas. Revista Online Fadivale. Governador Valadares. Ano XIII, n. 15, 2017.

BRASIL. Declaração de Salamanca e linha de ação sobre necessidades educativas especiais. Ministério da Ação Social. Coordenadoria Nacional Para Integração da Pessoa Portadora de Deficiência Brasília: MAS/CORDE, 1994.

Decreto $n^{\circ} 5.626$, de 22 de dezembro de 2005. Regulamenta a Lei no 10.436, de 24 de abril de 2002, que dispóe sobre a Língua Brasileira de Sinais - Libras, e o art. 18 da Lei no 10.098, de 19 de dezembro de 2000. Presidência da República. Brasília: Impressa Oficial, 2005. 
Lei $n^{\circ}$ 10. 436, de 24 de abril de 2002. Dispõe sobre a Língua Brasileira de Sinais - Libras e dá outras providências. Presidência da República. Brasília: Imprensa Oficial, 2002.

CALDEIRA, J. C. L et al. Programa Comunicar. Belo Horizonte: Clínica-Escola Fono, BRASIL, MEC. 5v, 1998.

CAPOVILLA, F. C.; CAPOVILLA, A. G. S. Educação da criança surda: o bilinguismo e o desafio da descontinuidade entre a língua de sinais e a escrita alfabética. Revista Brasileira de Educação Especial, Marília, v.8, n.2, p.127-156, maio, 2002.

. et al. O desafio do bilinguismo na educação do surdo: descontinuidade entre a língua de sinais e a escrita alfabética e estratégias para resolvê-la. In: Neuropsicologia e aprendizagem: uma abordagem multidisciplinar. Edição, normalização bibliográfica, revisão, editoração eletrônica: Fernando C. Capovilla. 2005.

COSTA, A. C.; STUMPF, M. R.; FREITAS, J. B.; DIMURO, G. P. Um convite ao processamento da língua de sinais. Disponível em: <http://gmc.ucpel.tche.br/TIL2004/til-2004slides.pdf>. UCEPEL-RS, PGIE / UFRGS, RS, PPGC / UFRGS, RS, Brasil. Acesso em 06 maio 2016.

NOVAES, E. C. N. Surdos: Educação, Direito e Cidadania. 2a ed. WAK Editora: Rio de Janeiro, 2014.

PÊGO, C. F. Sinais Não-Manuais Gramaticais da $L S B$ nos traços morfológicos e lexicais. Um estudo do Morfema-Boca. 2013. 88f. Dissertação (Mestrado em Linguística). Universidade de Brasília, DF, 2013.

PERLIN, G. T. O lugar da Cultura Surda. In: THOMA, A. S.; LOPES, M. C. (orgs.). A invenção da surdez. cultura, alteridade, identidades e diferença no campo da educação. Santa Cruz do Sul: EDUNISC, p. 73-82, 2004

QUADROS, R. M. de; KARNOPP, L. Língua de sinais brasileira: estudos lingüísticos. ArtMed: Porto Alegre, 2004.

STUMPF, M. Aprendizagem De Escrita De Língua De Sinais Pelo Sistema Signwriting: Línguas De Sinais No Papel E No Computador. Porto Alegre: UFRGS, 2005. Tese (Doutorado Em Informática Na Educação), Pós-Graduação em Informática na Educação, Universidade Federal Do Rio Grande Do Sul, 2005.

Transcrições de Língua de Sinais Brasileira em SignWriting. III Congresso Ibero-Americano de Informática na Educação Especial; Fortaleza, 2002. 
SILVA, T. S. A.; BOLSANELLO, M. A.; SANDER, M. E. Perspectivas para o ensino da escrita de alunos surdos usuários de Libras. Teoria e Prática da Educação, Maringá, v. 14, n. 3, p. 3541, set./dez. 2011.

STROBEL, Karin. As imagens do outro sobre a cultura surda. Florianópolis: Ed. da UFSC, 2008.

Edmarcius Carvalho Novaes: Aluno do Programa de Doutorado Interdisciplinar em Ciências Humanas pela Universidade Federal de Santa Catarina. Mestre pelo Programa Interdisciplinar em Gestão Integrada do Território da Universidade Vale do Rio Doce (2016). Tem especializações em Docência para o Ensino Superior; Educação e Inclusão Linha de Formação: Libras; Gênero e Diversidade na Escola; Direito Público e em Gestão Pública. Possui MBA em Administração Pública e Gestão de Cidades. É bacharel em Direito e licenciando em Filosofia. Atualmente é professor e pesquisador da Universidade Vale do Rio Doce.

E-mail:edmarcius@hotmail.com

Edmara Carvalho Novaes: Mestranda em Gestão Integrada do Território pela Universidade Vale do Rio Doce. Especialista em Educação e Inclusão - Língua Brasileira de Sinais; Graduada em Letras/Inglês e em Ciências - Licenciatura Plena em Matemática. Professora de Libras na UNIPAC - Governador Valadares.

E-mail:edmaracn@hotmail.com

JÉSSICA ROCHA dE MOURA: Especializando em Mídias para a Educação pela UFJF. Graduada em Pedagogia pela Universidade Vale do Rio Doce.

E-mail: jessika0302@hotmail.com 